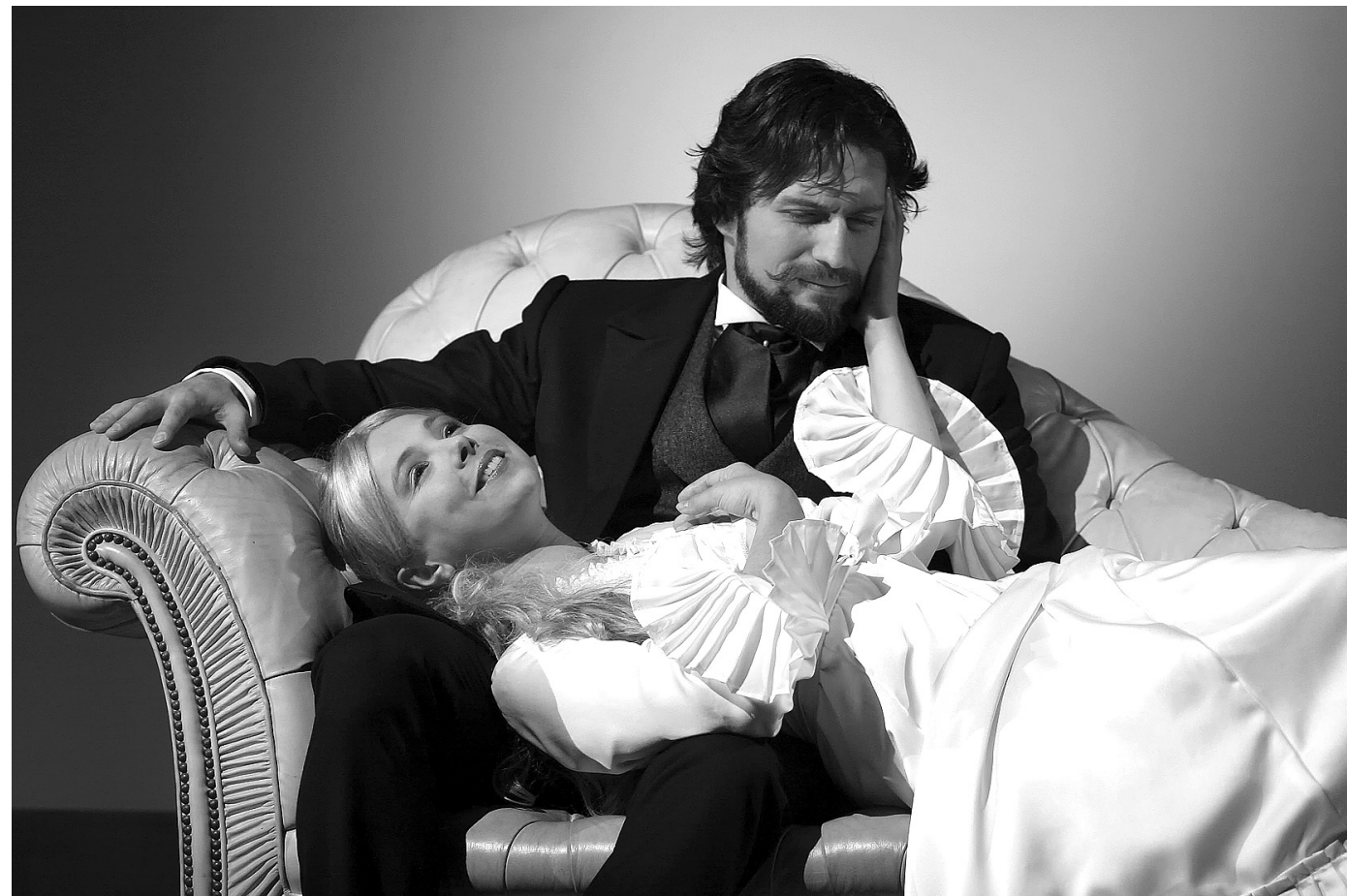

Os Maias no Trindade de António Torrado, enc. Rui Mendes, Teatro da Trindade, 2009 (José Fidalgo e Sofia Duarte Silva), fot. Clementina Cabral.

\title{
No Salão da Trindade
}

\section{Ana lsabel Vasconcelos}

Título: Os Maias no Trindade (2009). Autor: António Torrado, a partir de Os Maias de Eça de Queiroz. Encenação: Rui Mendes. Cenografia e Figurinos: Ana Paula Rocha. Direcção musical: Afonso Malão. Desenho de luz: Carlos Gonçalves. Desenho de esgrima: Mestre Eugénio Roque. Video: Adriano Filipe e Cristina Novo. Interpretação: Afonso Malão, Augusto Portela, Bruno Batista, Henrique Malta, Igor Sampaio, João Didelet, José Airosa, José Fidalgo, Luís Alberto, Luís Mascarenhas, Mário Jacques, Mário Rui, Pedro Górgia, Rui Sérgio, Rogério Vieira e Sofia Duarte Silva. Local e data de estreia: Teatro da Trindade, Lisboa, 5 de Fevereiro de 2009.

0 espectáculo Os Maias no Trindade, a partir do romance de Eça de Queiroz, foi muito mais do que uma peça em cena num dos mais emblemáticos teatros de Lisboa. $\mathrm{Na}$ verdade, este espectáculo integrou um projecto plurifacetado que contemplou sessões com especialistas da obra queirosiana, uma exposição sugestivamente intitulada "Eça em caricatura", que ocupou profusamente o espaço do Salão Nobre do teatro, uma mostra de filmes baseados em obras do escritor, bem como visitas guiadas ao próprio edificio.

Esta conjugação de acontecimentos e actividades, despoletados pela representação de um texto, cujo conteúdo tem, como referente, um dos mais conhecidos romances da literatura portuguesa, teve a melhor recepção por parte do público, que cedo esgotou as marcações das visitas, os bilhetes de ingresso e participou entusiasticamente nos encontros. Quando quisemos revisitar o espectáculo, cerca de três semanas antes do termo das representações, o Trindade tinha esgotado! Provavelmente um dos responsáveis por este sucesso terá sido o público escolar, que já há algum tempo acorre às salas de teatro sempre que se apresentam clássicos da literatura nacional. Esta é, indubitavelmente, uma forma aliciante de cativar os alunos para a leitura, através do apelo que a dimensão visual introduz, hoje mais do que nunca, na construção do imaginário literário. E é também assim que se podem ir criando os gostos, os hábitos e, com eles, a necessidade...

No texto que abre o Programa, assinado pelo Presidente da Fundação INATEL, organismo que tutela o Teatro da Trindade, destacam-se três nomes como principais responsáveis por esta iniciativa: Duarte Ivo Cruz, a quem se deve a ideia; António Torrado, a quem se deve a autoria do texto dramático; e Rui Mendes, a quem se deve a encenação. Os Maias, de Eça de Queiroz, obra-prima da literatura portuguesa, não será demais sublinhá-lo, surge como o "pré-texto", aproveitado para "[se] pôr em cena um extraordinário fresco da sociedade portuguesa do séc XIX"1. A intervenção que se segue nesse Programa é de António Torrado e reproduz o Prefácio ao texto dramático publicado em livro, cujo título significativamente coincide com o anunciado no cartaz: Os Maias no Trindade.

Embora perfilhemos a tese que estabelece a distinção entre a esfera do teatro e a da literatura e recusemos uma atitude filológica na abordagem do espectáculo, neste caso é-nos dificil olhar para o objecto cénico esquecendo o texto que lhe deu vida, tarefa que temos facilitada, já que o mesmo foi publicado simultaneamente à produção teatral. Esclarece-nos o mencionado Prefácio que se trata de uma peça em dois actos, "a partir do romance Os Maias", evitando-se prudentemente a expressão "adaptação", uma
Programa do espectáculo, p. 5. Lisboa, Fundação Inatel 2009 , p. 3.

Ana lsabel Vasconcelos é Professora da Universidade Aberta e investigadora do Centro de Estudos de Teatro da Universidade de Lisboa. 
vez que esta poderia implicar compromissos que de forma deliberada aqui se não tomam. Aliás, ao jeito do que habitualmente se fazia nos prólogos que precediam os dramas oitocentistas, António Torrado aproveita para justificar a sua opção: "fidelidade ao espirito da obra que servisse um espectáculo fluente, multiplicador de sentidos, dedutiveis da matriz romanesca", declinando a imediata transposição do discurso queirosiano para o diálogo dramático. As razões são óbvias e compreensíveis: "0 que na intimidade da leitura, nos parece correntio e de difícil elocução, ganha, por vezes, quando erguido no palco, um meneio e floreio incompativeis com a economia teatral" ${ }^{2}$ esclarece o autor. Sem dúvida que a longa experiência de António Torrado Ihe concede toda a autoridade nesta matéria.

Concretizando a intenção clara de subverter a ordem cronológica dos factos, esta versão da história inicia-se, precisamente, com o teatro dentro do teatro, querendo esta expressão aqui significar que foram recriados, no palco, dois camarotes do Trindade de 1876, ano em que, na ficção, Carlos e Ega vão assistir a um sarau de beneficência, sendo este, sem dúvida, um dos episódios fundamentais da narrativa.

Apesar da imprecisão espacial, já que o sarau teve lugar no "Salão da Trindade" (espaço contíguo ao teatro, então destinado a bailes, conferências e concertos), saudamos a escolha deste momento para a abertura, uma vez que, neste primeiro "quadro", se começam a gizar, com a economia dramática que o teatro exige, os diversos tipos de personagens que dão colorido a um dos pilares da peça: a crónica social. 0 facto de a acção se apresentar por núcleos temporais e espaciais não sequenciados, mas que por vezes, coabitam no espaço cénico, obrigou a um jogo cenográfico que favoreceu o desenvolvimento ritmado do espectáculo, exigindo, a nível da compreensão do enredo uma atenção redobrada por parte do espectador. A articulação cénica dos diferentes espaços de representação é habilmente orquestrada por jogos de luzes que vão enquadrando o desenrolar das cenas, correspondendo estas a momentos ora de avanço ora de recuo no fio cronológico da intriga. A facilitar esta fragmentação do espaço está o

${ }^{3}$ Ibidem, p. 82. facto de a cenografia ter optado por trazer para o palco apenas os elementos essenciais, caracterizadores mais do ${ }^{4}$ Eça de Queiroz, local da acção do que do ambiente de época.

Os Maias, Fixação do texto e notas de Helena em determinado passo este alter-ego de Eça retira-se da sua pele, assume a voz do autor e comenta, num momento crucial, o fio dos acontecimentos: "E porque é que nós não havíamos também de encerrar tudo aqui, neste episódio risonho? Era um bom desfecho... 0 Carlos, vingado. 0 Dâmaso, arrumado. 0 caminho, finalmente desimpedido para que Carlos e Maria Eduarda pudessem dar livre curso à paixão que os unia." ${ }^{3}$ Para além da comicidade inscrita em muitas das falas de Ega, José Airosa compõe uma figura bem conseguida, com um ligeiro tom a lembrar o famoso António Silva, tom esse empregue com acerto e moderação, numa aparência que faz jus à descrição queirosiana: "figura esgrouviada e seca, os pêlos do bigode arrebitados sob o nariz adunco, um quadrado de vidro entalado no olho direito - tinha realmente alguma coisa de rebelde e de satânico." ${ }^{4}$

No que diz respeito ao amigo de Ega, o actor que o interpreta, José Fidalgo, compõe, no perfil físico, no vestuário e até na postura, a imagem que facilmente identificamos como sendo Carlos da Maia, correspondendo ao imaginário que construimos da figura do dandy oitocentista. Quanto ao seu desempenho, fá-lo sem energia, fruto não de um traço caracterizador da personalidade, mas antes de uma actuação pouco convincente e nada empática, sendo, não raro, dificil entender as suas falas. A fraca utilização dos recursos de que um actor dispõe para compor a sua dramatis persona foi sobretudo prejudicial no momento que reconhecemos como sendo o climax da peça. Na verdade, a cena em que Ega revela ao amigo o segredo de família é destituída de qualquer tensão dramática, o que compromete o clima de tragédia tão necessário à criação do ambiente em que se vão precipitar os acontecimentos seguintes - incesto consciente morte de Afonso, partida de Carlos e Ega.

Ao longo da peça, a interacção verbal nem sempre se pautou pelo ritmo imprimido pelo jogo cénico, a que atrás já aludimos. Por outro lado, as trocas dialógicas ressentiram-se de imperfeições na dicção e de deficientes projecções de voz, o que fragilizou o resultado final, já que este tipo de teatro vive essencialmente da apreensão do texto dito.

Para além das duas personagens centrais acima referidas e das chamadas figuras funcionais, deste universo construido fez parte um outro grupo, cuja passagem pelo palco foi mais ou menos fugaz consoante a sua importância na acção, não se distinguindo em particular qualquer desempenho de mérito ou demérito que destoasse deste conjunto. Estamos a referir-nos a Cohen (Luis Mascarenhas), a Castro Gomes (Augusto Portela), ao Conde de Gouvarinho e a Vilaça (Igor Sampaio), bem como ao próprio Guimarães (Mário Jacques). 

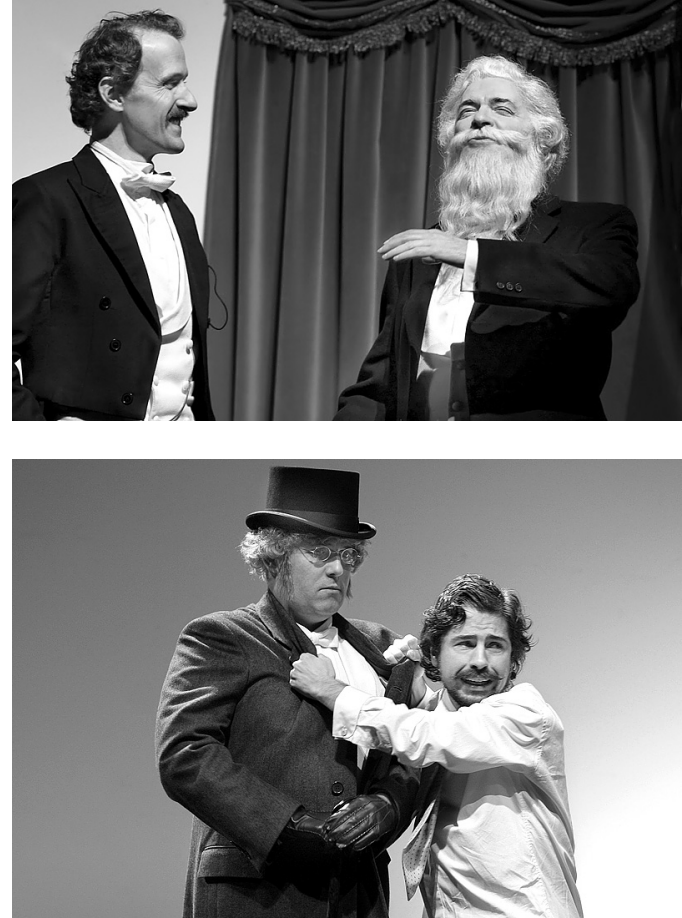

Dos diversos tipos sociais caricaturados, destacaramse aqueles que tiveram intervenção directa no sarau: Rufino, o deputado, interpretado por João Didelet, que acompanha o tom declamatório do discurso com largos gestos, acentuando a vertente caricatural da figura; Dâmaso, um rapaz "baixote, gordo e frisado como um noivo de província" ${ }^{5}$, a que Pedro Górgia dá corpo, com momentos de alguma comicidade, ficando muito aquém da figura marcante que conhecemos do romance; e Alencar que, representado por Rogério Vieira, consegue provocar em nós um distanciamento irónico, mas complacente, com uma actuação bastante equilibrada.

Afonso da Maia, desempenhado pelo actor Luís Alberto, marca sobretudo presença na figura de pai de Pedro, nas primeiras cenas da peça. Ai é-nos dado a conhecer um Afonso condescendente para com as aventuras amorosas do filho, mas inflexivel quando este se quer ligar pelo casamento com alguém de outro nível social. Não sendo sempre legiveis e acertadas as emoções transmitidas por esta personagem - recordemos a debilidade da cena em que supostamente segura o bebé embrulhado num cobertor -, o momento de ruptura com Pedro é bem conseguido, quando, sem qualquer comentário verbal ao que the acabara de acontecer, dá, com a voz endurecida mas não alterada, a seguinte ordem ao Vilaça: "Diga ao Teixeira que sirva o almoço. E que tome atenção: daqui para diante há só um talher à mesa. 0 meu." 6

Para além da crónica social, a intriga assenta, como se sabe, na relação amorosa que Carlos mantém com Maria Eduarda, esta aqui interpretada por Sofia Duarte Silva e aproveitada também para executar o papel breve que Maria Monforte tem nesta peça. Sabemos que as cenas de paixão "vividas" em palco podem facilmente cair no desequilibrio e assumir um tom patético, com efeitos até confrangedores. Dois factores evitaram esta situação: a brevidade justificada das mesmas e a prestação da actriz que construiu uma Maria Eduarda menos enigmática do que a do romance, mas mais consentânea com a

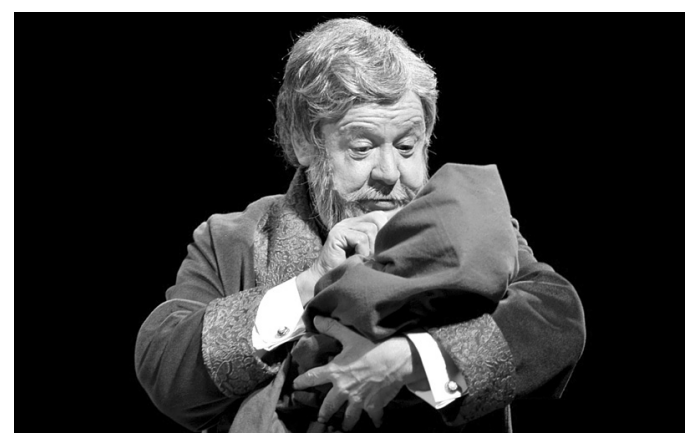

$<>$

Os Maias no Trindade

de António Torrado,

enc. Rui Mendes,

Teatro da Trindade, 2009

(< José Airosa

e Mário Jacques;

$>$ Luis Alberto;

$\checkmark$ Afonso Malão

e Pedro Górgia), fot. Clementina Cabral.

personagem, cuja verdadeira identidade já tinha sido revelada ao espectador. Para além da simplicidade e da sobriedade na actuação, a seu favor está a imagem de uma mulher bela, alta e loura, por quem Carlos logo se apaixonou.

A música, uma das linguagens mais conseguidas neste espectáculo, foi parcialmente executada ao vivo, num piano, cuja colocação, ao nível da plateia, anulou, de certa forma, a distância entre o espaço cénico e o espaço do público. Este piano foi magnificamente tocado por Afonso Malão que, no papel de Cruges e apesar de pouco participante na acção, pautou as suas intervenções por um traço distintivo. Não existindo muitos estudos sobre os elementos musicais na obra de Eça, é notável o cuidado na escolha das composições e a forma como se explorou o seu valor semiológico, em que cada trecho foi introduzido para acrescentar sentido à palavra, apoiar a acção ou sublinhar o adensar do clima dramático. Disto mesmo, mas com mais propriedade e sapiência, nos fala o texto incluso no programa e da autoria do próprio Afonso Malão, cuja leitura se não dispensa se quisermos perceber aquilo que é fugaz, em termos de compreensão, mas, por uma magia do indizivel, nos torna particularmente receptivos ao que se passa em cena e nos proporciona os momentos mais próximos da fruição estética deste espectáculo. De salientar o passo em que Cruges dialoga com Carlos, retorquindoIhe apenas por meio de breves apontamentos musicais.

As duas últimas cenas passam-se 10 anos mais tarde. Na sequência da projecção fílmica de abertura, que, simulando um filme antigo, mostrou a chegada de Carlos e Ega ao Trindade, ocupa agora o fundo da cena a gravura da Avenida da Liberdade da Lisboa oitocentista. Após um breve diálogo, em que os dois amigos lamentam o terem falhado no amor e na vida, o espectáculo termina, sublinhando-se esta atitude de desencanto e desistência e atenuando-se o carácter ambíguo e contraditório com que Eça caracterizou estas duas personagens centrais

Neste sentido, suprimiu-se a última imagem que retemos do romance queirosiano, em que "os dois amigos romperam a correr desesperadamente pela Rampa de Santos e pelo Aterro, sob a primeira claridade do luar que subia"7 , e optou-se pela imobilização física dos dois actores em cena. Este remate vem reforçar o "pessimismo vencidista" espelhado nas palavras quase finais que ouvimos a Carlos e a Ega: "Os esforços, todos os esforços são inúteis. [...] Nem a glória nem o dinheiro nos farão correr."8

E o que levamos depois das últimas notas do piano de Cruges? Mais do que um espectáculo que nos proporcionou o revisitar de uma história representada em pinceladas, ficou-nos a vontade de voltar ao romance original. Esta é uma das virtudes essenciais do projecto que Ihe deu vida.
Queiroz, op. cit., p. 725.
Torrado, op. cit., p. 15. 